\title{
De Profundis e Oscar Wilde: a pessoa, o escritor e o inscritor na autoria e o texto como gestão do contexto
}

\section{De Profundis and Oscar Wilde: the person, the writer and the inscritor in authorship and text as context management}

Kelen C. Rodrigues

UFU

kelenmanzan@yahoo.com.br

Resumo: Este artigo fundamenta-se na concepção de autoria proposta por Dominique Maingueneau (2006), que permite mostrar a autoria como um funcionamento entrelaçado de instâncias autorais. Buscarei mostrar a operacionalidade de conceber a autoria a partir de três instâncias discursivas, nomeadas pelo autor como a pessoa, o escritor e $o$ inscritor, na epístola De Porfundis, de Oscar Wilde. O texto em questão é uma correspondência que Wilde escreveu a Lord Douglas, seu amante, no período em que esteve na prisão, condenado por crime de indecência grave. O objetivo é apresentar com certa exaustividade essas instâncias em funcionamento na epístola e como, por meio de embreantes que se constituem no / pelo texto, validar o postulado do texto literário como gestão do contexto de sua produção.

Palavras-chave: funcionamento da autoria; correspondência; análise do discurso literário; Oscar Wilde. 
Abstract: This paper is based on the conception of authorship proposed by Dominique Maingueneau (2006). This concept allows us to show the authorship as an interlaced operation of discursive instances. I will seek to show how productive is conceive the authorship based on the functioning of three discursives instances -, named by the author as a person, the writer and the inscritor - in the epistle De Profundis by Oscar Wilde. This epistle is a letter wrote by Wilde to Lord Douglas, his lover, during the time Wilde was in prison, sentenced of gross indecency crime. The aim here is to present these discursive instances operating in De Profundis epistle, and how through shifters that are constructed in / by the text, so as to validate the postulate of the literary text as the managing context of their production.

Keywords: functioning of authorship; letters; literary discourse analysis; Oscar Wilde.

Recebido em 29 de abril de 2015. Aprovado em 02 de setembro de 2015.

\section{Considerações iniciais}

De acordo com as premissas da perspectiva teórica adotada para o tratamento do objeto literário, não há como apagar o componente biográfico, o que não significa que a obra seja um reflexo da biografia de seu autor, ou de sua época (ou de ambos), tampouco seja fruto de uma instância criadora autossuficiente. Diferentemente, a abordagem como proposta por Dominique Maingueneau (2006) implica conceber as três instâncias (a pessoa - com sua biografia; o escritor - que tem que seguir e ter rituais do campo literário; e o inscritor - que é o que emerge do texto, relacionado diretamente com a questão textual e genérica) de forma imbricada, já que se afetam mutuamente.

Outro ponto que torna a abordagem do fenômeno literário mais operacional, diz respeito aos dois regimes enunciativos propostos pelo autor para tratar os diferentes regimes de enunciação, nomeados como regime delocutivo e regime elocutivo. Esses dois regimes, tem seu funcionamento imbricado, não prolongando a questão do enquadramento dos textos de um autor em termos literários ou não literários. 
A Análise do Discurso Literário não busca a explicação da obra por seu autor, ou o caminho inverso. A questão principal remete ao funcionamento dos discursos. Todavia, para compreender tal funcionamento, faz-se necessário agrupar princípios que sejam produtivos e explicativos de tais discursos. E, pois, nesse sentido, que analisar o funcionamento da autoria, como será feito neste artigo, é assumir um caminho para a compreensão da literatura em termos de regimes de enunciação, assim como em termos do texto como gestão do contexto.

Assume-se essa concepção de autoria proposta por Maingueneau, porque ela permite demonstrar que o que está no texto de um autor, no caso Oscar Wilde, diz respeito à pessoa de Wilde, tem relação com sua função de escritor no campo literário por conta de um determinado posicionamento e diz respeito a uma criação estética, à obra em si, ao trabalho enunciativo de um inscritor. Além disso, a noção de autor formulada pelo analista do discurso francês permite conferir a certos gêneros de discurso produzidos no campo da literatura, como é o caso da correspondência escrita na prisão por Wilde ao seu amante Lord Douglas, um estatuto que está para além de seus valores documental e biográfico, permitindo analisar a literatura como uma forma de gestão do contexto de sua produção.

\section{A proposta de uma autoria em funcionamento}

Maingueneau (2006) propõe que a questão da autoria seja considerada a partir de três instâncias discursivas: a pessoa, o escritor e $o$ inscritor. A pessoa refere-se ao indivíduo dotado de um estado social, de uma vida privada. O escritor é uma espécie de ator que traça um caminho e desempenha um papel na instituição literária. Por fim, o autor (Ibid., 2006, p. 136) esclarece que, em relação ao neologismo inscritor, "ele subsume ao mesmo tempo as formas de subjetividade enunciativa da cena de fala implicada pelo texto (aquilo que vamos chamar de "cenografia") e a cena imposta pelo gênero de discurso: romancista, dramaturgo...". $\mathrm{O}$ autor afirma ainda que essa noção de inscritor valida-se tanto no oral como no escrito.

Não há, entretanto, um primeiro plano para a pessoa, seguida do "ator" literário, o escritor, que culminaria em seguida no inscritor, o sujeito da enunciação. Essas três instâncias não são cronológicas, estratificadas ou mesmo sequenciais, mas são atravessadas umas pelas 
outras, de modo que "cada uma das três sustenta as outras e é por elas sustentada, num processo de recobrimento recíproco que, num mesmo movimento, dispersa e concentra "o" criador" (Ibid., p. 137). Todavia, é possível, para efeitos de análise, mostrar de que forma pode ocorrer a preponderância de alguma delas sobre as outras, o que não significa reduzi-las ou isolá-las.

Na esteira da "problemática da obra", e com o intuito de deslocar a recorrente indagação do que seria literário ou não na produção de autor para a questão do funcionamento da autoria, assume-se que a literatura mescla dois regimes: um regime delocutivo e um regime elocutivo. No regime delocutivo, o autor se oculta diante dos mundos que instaura; no elocutivo, o inscritor, o escritor e a pessoa, conjuntamente mobilizados, deslizam uns nos outros.

Maingueneau coloca como dominante, na apreensão do fato literário, as obras que ocultam, fundamentalmente, a pessoa e o escritor, isto é, o regime delocutivo de enunciação literária, embora a literatura não seja um espaço estável, uma vez que, cada vez mais, produções do regime de enunciação elocutivo têm sido alçadas à categoria de "cânone", como é o caso da epistola De Profundis de Oscar Wilde.

Para melhor apreensão do funcionamento do regime elocutivo, o autor propõe a ampliação de seu quadro teórico, postulando a existência de duas dimensões: a de figuração e a de regulação. Essas duas dimensões, embora distintas, são também inseparáveis. A primeira concentra a encenação do criador, por meio da qual o autor busca construir uma identidade criadora no mundo criado. Em relação à dimensão de regulação, podemos dizer que ela envolve a tentativa, por parte do criador, de inserir seu texto em um dado momento no campo e nos circuitos convenientes. O autor destaca ainda (Ibid. p. 143) que um manifesto ou um prefácio tem, de modo geral, essa função reguladora de inserção das obras em conformidade com as normas, "seja para mostrar que seguem as normas existentes ou para propor soberanamente as do autor".

Ampliando toda essa conceituação, ele ainda destaca que um autor tem sua produção associada a dois espaços discursivos indissociáveis, que não se encontram, entretanto, em um mesmo plano, e convencionou chamá-los de espaço canônico e espaço associado.

Sobre o espaço canônico, o autor esclarece que ele abrange a maioria dos textos do regime delocutivo e que "ele não se reduz a um espaço em 
que mundos ficcionais teriam um "eu" referencialmente ao do autor" (Ibid., p. 144), mas "repousa numa dupla fronteira: entre os actantes do mundo ficcional e o autor, de um lado, e entre "inscritor" e "escritor" - "pessoa", do outro" (Ibid., 144), sendo, assim, altamente ritualizado.

Com relação à natureza do espaço associado, ela varia de acordo com o espaço canônico, o que não significa que seja um adendo contingente que se adicionaria, a partir de fora, a esse espaço. Contrariamente, há um movimento de eterna negociação entre esses dois espaços, que implica indistinção das fronteiras que estruturam a instância enunciativa. É, pois, nesse sentido que Maingueneau (2006, p. 146) afirma que

o discurso literário não é um território compacto que gera simplesmente algumas dificuldades locais de estabelecimento de fronteiras, mas um espaço radicalmente duplo. Funciona com base num duplo movimento de desconexão (no espaço canônico) e de conexão (no espaço associado) das instâncias subjetivas.

Esses movimentos são complementares e contraditórios a um mesmo tempo, e é da impossibilidade de estabilizá-los que advém um dos propulsores da produção literária.

$\mathrm{O}$ conceito de autoria e a problemática que a ele se vincula mostram-se produtivos e relevantes não só para propor um novo tipo de abordagem do fato literário mas também como uma contrapartida a análises que relacionam de forma direta a biografia de um autor e sua obra.

\section{De Profundis: a pessoa, o escritor e o inscritor}

Com relação ao texto De Profundis, trata-se de uma carta que Wilde escreveu a seu amante Lord Alfred Douglas (o Bosie), no período em que o autor estava no cárcere, condenado pelo crime de indecência grave. Wilde levou três meses para escrevê-la e, quando a finalizou, pediu aos comissários da prisão que a enviassem para Robert Ross, o tutor de sua obra, para que ele fizesse duas cópias da epístola e enviasse a original a Lord Douglas. Entretanto, como nos relata o neto de Wilde, Merlin Holland, a carta não foi enviada a ninguém e, na saída da prisão, foi devolvida a seu autor. $\mathrm{O}$ trecho a seguir oferece uma boa visão da problemática que envolveu esse escrito até sua publicação completa em 1962: 
Em seguida, no início de 1897, ele deu início à sua carta a Douglas. Dentro de três meses ele a concluiu e sua intenção era enviar para Robert Ross, que teria que datilografar as cópias e enviar o original a Douglas. No entanto, os comissários da prisão não permitiram que a carta fosse enviada e instruíram Nelson, o prefeito, a guardá-la e devolvê-la ao prisioneiro na ocasião em que fosse posto em liberdade. [...] Ross, mais tarde, declarou que manteve o original e enviou uma das cópias para Douglas [...].

Em 1905, cinco anos após a morte de seu amigo, Robert Ross percebeu que era o momento certo de dar ao mundo uma versão expurgada da carta. [...] Em 1909, após a publicação de uma versão ligeiramente ampliada na Collected Works, Ross depositou o manuscrito no Museu Britânico com a condição de que ele ficaria selado por 50 anos. [...]Foi somente em 1949, quatro anos após a morte de Douglas, que meu pai finalmente foi capaz de publicar o trabalho do único exemplar datilografado que Ross havia mantido e legado a ele. Mesmo que estivesse cheio de erros e omissões, foi somente em 1962, quando o manuscrito foi aberto ao público, que a primeira versão completa e exata foi publicada em The Letters of Oscar Wilde." (tradução nossa). ${ }^{1}$

Para melhor apreensão de De Profundis, ela será dividida em três grandes eixos temáticos, identificados como: i) Bosie (apelido de Lord Alfred Douglas); ii) autorreflexão; iii) Deus. A opção por dividir o texto em eixos temáticos é para familiarizar o leitor com o texto analisado, fornecendo-lhe, ao mesmo tempo, uma visão geral da carta

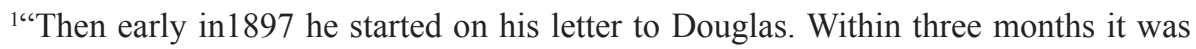
completed and his intention was to send to Robert Ross, who was to have to typed copies made and send the original to Douglas. However, the Prison Commissioners flaty refused to allow the letter to be sent out and instructed Major Nelson, the governor, to keep it and give it to prisoner on his release. [...] Ross, so he later testified, then kept the original and send one of the copies to Douglas $[\ldots]$.

In 1905, five years after his friend's death, Robert Ross felt that the time was right to give the world an expurgated version of the letter. [...] In 1909 after publishing a slighty enlarged version in the Collect Works, Ross deposited the manuscript in the British Museum with the proviso that it was to sealed for fifty years. [...] It was not until 1949, four years after Douglas's death, that my father was finally able to publish the work from the single typescript copy which Ross had kept and bequeathed to him. Even that was littered with errors and omissions and it was not until 1962, once the manuscript was open to the public, that the first complete and accurate version was published in The Letters of Oscar Wilde" (HOLLAND, 2003, p. 911-912).
} 
e do funcionamento da autoria. A sequência dos eixos temáticos não é aleatória, visto que busca manter-se fiel à sequência dos temas, tais como eles são apresentados em De Profundis.

O primeiro grande eixo temático da carta, Bosie, é sobre o jovem e a relação que os dois, ele e Wilde, mantiveram por mais de três anos. A carta se inicia com Dear Bosie, seguida de um relato pessoal:

Depois de uma longa e inútil espera, decido-me a escrever-te diretamente, tanto por ti como por mim, já que não me agrada pensar que passei dois intermináveis anos de reclusão sem receber nunca uma linha só de ti, sem notícias, nem tão-somente uma mensagem que não haja sido de um gênero que me entristece.

Nossa desgraçada e lamentabilíssima amizade acabou para mim na ruína e na vergonha pública; não obstante, acompanha-me com frequência a lembrança de nossa antiga intimidade e a ideia de que o ódio, a amargura e o desprezo tenham de substituir em meu coração o lugar que ocupava outrora o afeto torna-se muito triste para mim. Tu também sentirás, creio eu, em teu coração, que seria preferível escrever-me enquanto permaneço na solidão desta prisão que publicar minhas cartas sem minha permissão ou dedicar-me poemas sem me consultar, [...].

Não duvido nem um momento que nesta carta que devo escrever-te, a respeito de tua vida e da minha, do passado e do futuro, das gratas coisas trocadas em amargura, amargura que poderá converter-se em alegria, [...]. Se vais queixar-te a tua mãe, como fizeste por causa do desprezo para contigo que exprimi em uma carta a Robbie... (WILDE, 2007, p. 1343). ${ }^{2}$

\footnotetext{
${ }^{2}$ After long and fruitless waiting I have determined to write to you myself, as much for your sake as for mine, as I would not like to think that I had passed through two long years of imprisonment without ever received a single line from you, or any news or message even, except such as gave me pain.

Our ill-fated and most lamentable friendship has ended in ruin and public infamy for me, yet the memory of our ancient affection is often with me, and the thought that loathing, bitterness and contempt should for ever take that place in my heart once held by love is very sad to me: and you yourself will, I think, feel in your heart that to write to me as I lie in the loneliness of prison-life is better than to publish my letters without my permission or to dedicate poems to me unasked [...].

I have no doubt that in this letter in which I have write of your life and of mine, of the past and of the future, of sweep things changed to bitterness and of bitter things that
} 
Neste excerto, a instância que sobressai no funcionamento da autoria é a pessoa. Trata-se de um relato pessoal, de uma conversa direta com um interlocutor real, Bosie. Wilde relata como se sentia em relação à amizade dos dois e de como enxergava o fato de nunca ter recebido uma carta de Bosie. Entretanto, embora a instância da pessoa sobressaia, em um olhar mais detido, pode-se apontar a presença do escritor, que se mescla com a pessoa, em dois momentos: "Nossa desgraçada e lamentabilíssima amizade acabou para mim na ruína e na vergonha pública."; "seria preferível escrever-me enquanto permaneço na solidão desta prisão que publicar minhas cartas sem minha permissão ou dedicar-me poemas sem me consultar.". ${ }^{4}$

No primeiro excerto, a ruína e a infâmia pública atingiram não só a pessoa, como também a instância do escritor, que traçou (e traça) um percurso no campo literário. Além disso, a questão levantada por Wilde de ter suas cartas publicadas sem autorização e poemas dedicados a ele, é relevante, pois revela a interferência da instância do escritor, uma vez que isso apenas ocorre em função da notoriedade e da condição de escritor bem-sucedido, ou ao menos conhecido, na instituição literária.

No início da carta, Wilde dedica-se a descrever a personalidade do jovem, ao mesmo tempo em que inicia seu processo de autorreflexão (que permeia toda a correspondência), como será possível perceber nos trechos apresentados.

Continuas dizendo, como disseste, respondendo a Robbie, que te atribuo "intenções indignas"? Ah! Não tiveste intenções na vida. Só tiveste apetites. Uma intenção é um objetivo intelectual. [...]. Com a rápida marcha da carreira passaste da Ficção ao Realismo. A sarjeta e tudo quanto nela ferve começaram a seduzir-te. [...]. O verdadeiro louco, aquele de quem os deuses zombam ou a quem perdem, é o que não conhece a si mesmo. Fui um desses demasiado tempo. Foste também um desses demasiado tempo. Deixa de sê-lo. Não temas. O supremo vício é a estreiteza de espírito. Tudo quanto alguém compreende está bem.

may be turned into joy, [...]. If you go complaining to your mother, as you did with reference to the scorn of you displayed in my letter to Robbie... (WILDE, 2000, p. 03). 3 "Our ill-fated and most lamentable friendship has ended in ruin and public infamy for me". 4 "I lie in the loneliness of prison-life is better than to publish my letters without my permission or to dedicate poems to me unasked" (WILDE, 2007, p. 1343). 
Lembra ainda assim de que, por muito que te doa ler isto, maior é ainda minha dor ao escrevê-lo (WILDE, 2007, p. 1344). ${ }^{5}$

Embora o extrato anterior pareça privilegiar de maneira definitiva a instância da pessoa, seja pelo conteúdo temático, seja pela cenografia de correspondência íntima que se constrói, é possível perceber a instância do inscritor funcionando, pelo estilo que o trecho apresenta, especialmente pela presença da máxima "The supreme vice is shallowness" ( $\mathrm{O}$ supremo vício é a estreiteza de espírito). Da mesma forma, o escritor também se manifesta, nos trechos a seguir: "The real fool, such as the gods mock or mar, is he who does not know himself" (o aspecto dos deuses pagãos) e "Everything that is realised is right" (e a valorização a experiência para o autoconhecimento, preceitos reconhecidos do posicionamento esteto-decadentista de Oscar Wilde no campo literário). Esses aspectos podem ser observados em diversos trechos do romance Dorian Gray, como é possível aferir na conversa entre dois dos personagens centrais, Lord Henry Watton e o próprio Dorian Gray. Com relação aos deuses pagãos, Lord Henry manifestase dizendo: "Yes, Mr. Gray, the gods have been good to you. But what the gods give they quickly take away" (WILDE, 2003, p. 24) ("Sim, Sr. Gray, os deuses lhe foram propícios. Mas o que os deuses dão logo tiram" (WILDE, 2002, p. 34). No que diz respeito à valorização da experiência como forma de autoconhecimento, Lord Henry afirma a Dorian: "Be always searching for new sensations. Be afraid of nothing... A new Hedonism - that is our century wants"(WILDE, 2002, p. 25). ("Esteja sempre à cata de novas sensações. Nada tema...Um novo hedonismo...É isto que nosso século deseja." (WILDE, 2002, p. 35)).

${ }^{5}$ Do you still say, as you said to Robbie in your answer, that I "attribute unworthy motives" to you? Ah, you had no motives in life. You had appetites merely. A motive is an intellectual aim. [...] With very swift and running feet you passed from Romance to Realism. The gutter and the things that live in it had begun to fascinate you. [...] The real fool, such as the gods mock or mar, is he who does not know himself. I was such a one too long. You have been such a one too long. Be so no more. Do not be afraid. The supreme vice is shallowness. Everything that is realised is right. Remember also that whatever is misery you to read, is still greater misery to me to set down (WILDE, 2000, p. 03) 
No trecho seguinte da carta, Wilde em seu diálogo com Bosie, abre espaço para uma autorreflexão sobre essa amizade:

Começarei por dizer-te que me censuro a mim mesmo terrivelmente. Sentando nesta sombria cela, com traje de presidiário, como um homem arruinado e desonrado me censuro. [...]. Censuro-me por ter permitido que uma amizade não intelectual, uma amizade cujo primordial objetivo não foi a criação e a contemplação de belas coisas, dominasse por completo minha vida. Desde o princípio que existia entre nós um abismo demasiado grande. Havias sido folgazão no colégio, mais que preguiçoso na Universidade. Não compreendias que um artista, e especialmente um artista como eu o sou, isto é, em que a qualidade da obra depende da intensificação de sua personalidade, necessita de uma atmosfera intelectual de tranquilidade, de paz e de solidão. Admiravas minha obra quando estava terminada; conhecestes os brilhantes êxitos de minhas estreias e os seletos banquetes que a elas se seguiam; sentias-te orgulhoso, coisa muito natural, de ser amigo íntimo de uma artista tão distinto; [...] ... minha vida, enquanto estiveste a meu lado, foi inteiramente estéril, nada criadora." (WILDE, 2007, p. $1344-1345){ }^{6}$

Neste trecho, e como em inúmeros outros momentos da carta, é possível perceber a manifestação da instância do escritor, em um momento em que se tem a (falsa) sensação de que a instância da pessoa é a única que se manifesta. No excerto em questão, Wilde lamenta e se culpa, por ter permitido uma amizade, cujo objetivo principal não era a criação e a contemplação do belo, reafirmando sua inscrição como

${ }^{6 " I}$ I will begin by telling you that I blame myself terribly. As I sit here in this dark cell in convict clothes, a disgraced and ruined man I blame myself. [...] I blame myself for allowing an unintellectual friendship, a friendship whose primary aim was not the creation and contemplation of beautiful things, to entirely dominate my life. From the very first there was too wide gap between us. You had been idle at your school, worse than idle at your university. You did not realise that an artist, and especially such an artist as I am, that is to say, the quality of whose work depends on the intensification of personality, requires for the development of his art the companionship of ideas, an intellectual atmosphere, quiet, peace, and solitude. You admire my work when it was finished: you enjoyed the brilliant successes of my first nights, and the brilliant banquets that followed them: you were proud, and quite naturally so, of being the intimate friend of an artist so distinguished: $[\ldots]$... my life, as long as you were by my side, was entirely sterile and uncreative." (WILDE, 2000, p. 04-05) (grifo nosso). 
escritor esteto-decadentista. O preceito máximo desse posicionamento também é evocado no trecho, a saber, a transformação da vida em obra de arte que é materializada na frase: "the quality of whose work depends on the intensification of personality" (a qualidade da obra depende da intensificação da personalidade do artista).

O trecho também é significativo por que Wilde detalha a Bosie nuances de seu rito genético de criação (“" [... necessita de uma atmosfera intelectual de tranquilidade, de paz e de solidão"), que o legitimam como autor e sem os quais é impossível ao autor fazer uma obra. Nesse contexto, a presença de Bosie era um fator limitador do cumprimento desses ritos, como ele próprio afirma: "minha vida, enquanto estiveste ao meu lado, foi inteiramente estéril nada criadora" ${ }^{8}$ Esse não é o único momento em que Wilde relata, ao mesmo tempo, sobre a interferência negativa de Bosie em seu trabalho e os ritos genéticos requeridos para que um escritor esteto-decadentista escreva seus textos.

Wilde utiliza um mecanismo discursivo interessante, já presente na citação anterior, e que reaparece na citação a seguir. Nele, Wilde reconhece sua culpa, ele se culpa pelos acontecimentos e pelo rumo de sua vida. Todavia, esse reconhecimento ocorre por meio dos apontamentos dos defeitos de Bosie, como no trecho a seguir, em que Wilde se lembra de uma ocasião em que ele e a mãe de Bosie estavam juntos:

Censuro-me por ter permitido que me levasses à ruína financeira total e desonrosa. Lembro-me de que numa manhã, em princípios de outubro de 92, estava eu sentado nos já amarelentos bosques de Bracknell com tua mãe. [...] ... tua mãe começou a falar-me de teu caráter. Apontou-me teus dois principais defeitos: tua vaidade e teu "absoluto equívoco" em matéria de dinheiro, como o qualificou. Lembro-me perfeitamente de que me fez rir muito. Não tinha ideia de que a primeira me levaria ao cárcere, e a segunda, à bancarrota (WILDE, 2007, p. 1346-1347). ${ }^{9}$

\footnotetext{
${ }^{7 "[\ldots]}$ companionship of ideas, an intellectual atmosphere, quiet, peace, and solitude" (idem, ibidem).

8“"my life, as long as you were by my side, was entirely sterile and uncreative" (idem, ibidem).

9"I blame myself again for having allowed you to bring me to utter and discreditable financial ruin. I remember one morning in the early October of ' 92 sitting in the yellowing Woods at Bracknell with your mother. [...] ... your mother began to speak to me about your character She told me of your two chief faults, your vanity, and your
} 
Tem-se o mesmo mecanismo: a assunção "I blame myself again" ("censuro-me"), seguida de uma acusação a Bosie, "Não tinha ideia de que a primeira me levaria ao cárcere, e a segunda, à bancarrota.. ${ }^{10}$ Esse mesmo mecanismo é verificado duas páginas adiante: "Mas, por cima de tudo (sic), censuro-me pela completa degradação ética em que deixei que me afundasses." (WILDE, 2007, p. 1348)."1

Apresentar as características de Bosie contribuem não somente para que o leitor entenda melhor o texto como também reforça o caráter pessoal da carta e, embora a instância da pessoa possa parecer proeminente, pela própria cena genérica que assim favorece, a análise do texto mostra a inseparabilidade da pessoa, do escritor e do inscritor.

A carta é cheia de detalhes da amizade dos dois, incluindo os gastos que Wilde tinha com Bosie, que foram explicitamente relatados para complementar o egoísmo e a superficialidade que Wilde impõe a Bosie na carta. Nesse momento, ao relatar os milhares de pounds que foram gastos, ocorre, sem dúvida, a proeminência da instância da pessoa, que, todavia, não apaga o inscritor que, no meio da querela financeira, escreve em grego e pontua a carta com máximas, como: "faço-o constar simplesmente como um fato que rege todas as relações sociais. Pois, afinal de contas, a conversação é o nexo de todas, tanto no matrimônio quanto na amizade." (WILDE, 2007, p. 1352). ${ }^{12}$ Outro ponto, que revela a presença da instância do inscritor, é a recorrência de palavras e expressões em francês como moyen de vivre (meio de vida), attaché (ligação), entre outras, presentes nos textos do espaço canônico de produção do autor como um traço de estilo. Como exemplo dessa ocorrência, retoma-se o romance Dorian Gray e a personagem Lord Henry que, ao fornecer sua opinião sobre o sentimento da paixão, utiliza uma expressão em francês: "Uma grande paixão é o privilégio das pessoas que não têm o

being, as she termed it, "all wrong about money". I have a distinct recollection of how I laughed. I had no idea that the first would bring me to prison, and the second to bankruptcy." (WILDE, 2000, p. 7)

10"I had no idea that the first would bring me to prison, and the second to bankruptcy."(Ibid.).

11"But most of all I blame myself for the entire ethical degradation I allowed you to bring to me" (WILDE, 2000, p. 9).

${ }^{12}$ "Ultimately the bond of all companionship, whether in marriage or in friendship, is conversation" (WILDE, 2000, p. 13). 
que fazer." (WILDE, 2002, p. 62) ${ }^{13}$ Contudo, a presença dessas mesmas palavras e expressões também revela traços da instância do escritor, que se posiciona na interlíngua, ao mesmo tempo em que constitui o código linguageiro da obra. É, pois, por meio das instâncias do escritor e do inscritor que o autor se posiciona na interlíngua e é capaz de produzir um código linguageiro próprio para sua obra. Maingueneau (2006) diz que a língua é parte do complexo movimento por meio do qual uma obra se institui, mesmo que se tenha de deslocar a questão da língua para a interlíngua. Quando Wilde escreve Salomé (1893), drama em um ato, em francês, ele conjura aspectos do seu posicionamento, mas, ao mesmo tempo, esse gesto literário reforça uma prerrogativa muito forte, de séculos anteriores ao século 19, da universalidade da língua francesa, uma língua legítima para a produção literária, integrando, assim, o restrito círculo de autores não franceses a escrever um livro em francês.

Ainda em relação às análises do eixo I, é possível perceber que, em alguns momentos, a carta adquire um tom de tragédia, de drama, como quando Wilde descreve a tentativa, em vão, de não mais se encontrar com Bosie. Ele relata as cartas trocadas com a mãe de Bosie, com Bosie e, em uma das cartas trocadas com seu amante, faz o seguinte relato:

[...] recordavas-me que para ver-me somente uma hora tinhas viajado seis dias e seis noites, atravessando a Europa, sem te deteres nem uma só vez; reconheço que teu apelo era dos mais patéticos; e terminavas com o que me pareceu uma ameaça de suicídio, seu tanto quanto pouco velada. Tinhas-me dito com frequência que em tua família, eram muitos os que haviam manchado suas mãos com seu próprio sangue: teu tio, com certeza, e teu avô, provavelmente, e outros vários do insensato e perverso ramo a que pertences (WILDE, 2007, p. $1355-1356) .{ }^{14}$

\footnotetext{
13“ A grande passion is the privilege of people who have nothing to do"(WILDE, 2002, p. 48).

${ }^{14}[. .$.$] you reminded me that for sake of seeing me even for one hour you had travelled$ six days and nights across Europe without stopping once on the way: you made what I must admit was a most pathetic appeal, and ended with what seemed to me a threat of suicide, and one not thinly veiled. You had yourself often told me how many of your there had been who had stained their hands in their own blood; your uncle certainly, your grandfather possibly, many others in the mad, bad line from which you come (WILDE, 2000, p. 17-18)
} 
São vários os momentos em que Wilde descreve a personalidade de Bosie por meio de seus comportamentos. Apresentar todas as caracterizações seria quase como reproduzir a carta em toda sua extensão. Ainda assim, propõe-se ao leitor mais alguns desses momentos, que tanto fazem realçar a instância da pessoa. Destaca-se o relato de Wilde sobre quando Bosie estava doente e como Wilde tomou conta dele, mas logo em seguida, adquirindo, provavelmente por contágio, a gripe de Bosie, Wilde foi abandonado a sua própria sorte, com Bosie apenas aparecendo para pedir dinheiro e acusá-lo:

Acusaste-me de egoísta porque te havia rogado que estivesses ao meu lado, durante minha enfermidade; censuraste-me o interpor-me entre ti e tuas diversões, o tentar privar-te de teus amigos. Disseste-me, e sei que era verdade, que tinhas voltado à meia-noite somente para trocar de roupa e partir de novo para teus prazeres. [...]. Às onze da manhã, entraste em meu quarto. [...]. Como era natural, esperava eu ouvir as desculpas que devias alegar e tinha curiosidade de saber como te arranjarias para conseguir meu perdão, que, demasiado sabias, te concederia de bom coração. [...]. Mas, muito pelo contrário, repetiste o escândalo da noite anterior, com maior raiva e violência possível.

Finalmente, ordenei-te que saísses de meu quarto. Fingiste fazê-lo; mas quando levantei a cabeça do travesseiro, no qual havia afundado, continuavas ali e, com a brutalidade da risada e o histerismo da raiva, avançaste para mim. [...]. Passada uma hora, tendo chegado o médico, encontrou-me, naturalmente, num estado de completo abatimento nervoso [...]; silenciosamente, voltaste a buscar dinheiro (WILDE, 2007, p. $1358-1359){ }^{15}$

15 "You accused me of selfishness in expecting you to be with me when I was ill; of standing between you and your amusements; of trying to deprive you of your pleasures. You told me, and I know it was quite true, that you had come back at midnight simply in order to change your dress-clothes, and go out again [...]. [...] At eleven o'clock you came into my room [...]. [...] I waited naturally to hear what excuses you had to make, and in what way you were going to ask for the forgiveness that you knew in your heart was invariably waiting for you, no matter what you did; [...] so far from doing that, you began to repeat the same scene with renewed emphasis and more violent assertion. I told you to leave the room: you pretend to do so, bur when I lifted up my head from the pillow in which I had buried it, you still there, and with brutality of laughter and hysteria of rage you moved suddenly towards me. [...] After an interval of an hour, 
Wilde estabelece um diálogo com Bosie, fazendo perguntas diretas (e retóricas!) a ele: "Não necessito dizer...; "tampouco necessito dizer-te..." (WILDE, 2007, p. 1359). ${ }^{16}$ Wilde também detalha as inúmeras tentativas que fez para se afastar de Bosie e como falhou em todas. Nesse momento, a instância da pessoa se manifesta pelo diálogo encenado na carta entre os dois. O interessante é que todas essas tentativas são descritas por Wilde da seguinte maneira: Wilde relata ter consciência do quão destrutiva é a amizade dos dois; segue-se a isso um relato de um comportamento inaceitável de Bosie em relação a Wilde; em seguida, vem a determinação de Wilde em pôr fim a essa amizade, seguido pelo anticlímax, que é ele voltando atrás em sua decisão, em virtude de algum acontecimento triste ou por uma razão nobre, e concedendo a Bosie mais uma chance. Esse constitui-se como um segundo mecanismo discursivo que se constitui na carta: a apresentação de uma tentativa de rompimento, seguida da não concretização da ação.

É o que acontece no episódio em que relata a morte do irmão de Bosie, estampada em um jornal inglês, no exato dia em que Wilde estava decidido a escrever ao pai de Bosie, assegurando-lhe que jamais voltaria a se encontrar com seu filho. Todavia, diante da tragédia, como poderia ele ficar imune ao sofrimento de Bosie e de sua mãe? É o que Wilde diz: "Não podia portar-me contigo como fizeras durante minha enfermidade, diante daquela perda tão dolorosa que sofrias." (WILDE, 2007, p. 1361). ${ }^{17}$ Esse excerto não só ilustra o mecanismo descrito como também dá indícios de que Wilde busca construir um ethos $^{18}$ de benevolência, de superioridade de espírito, em contraposição ao antiethos que busca construir para Bosie: "Não podia portar-me contigo como fizeras durante minha enfermidade, diante daquela perda tão dolorosa que sofrias. [...] Pois me pareceu terrível deixar-te sozinho entre estranhos numa situação como aquela." (WILDE, 2007, p. 1361). ${ }^{19}$ Wilde ainda fornece indícios

during which the doctor had came and found me, of course, in a state of absolute nervous prostration, [...] you returned silently, for money [...]" (WILDE, 2000, p. 21) ${ }^{16 " N e e d ~ I ~ t o ~ t e l l ~ y o u . . . ? " ; ~ " i s ~ i t ~ n e c e s s a r y ~ f o r ~ m e ~ t o ~ s t a t e . . . ? " ~(W I L D E, ~ 2000, ~ p . ~ 22) . ~}$

17 "What you had been to me in my sickness, I could not be to you in your bereavement" (WILDE, 2000, p. 24).

${ }^{18} \mathrm{O}$ conceito de ethos será abordado nas considerações finais.

19 "What you had been to me in my sickness, I could not be to you in your bereavement. [...] I felt that to abandon you at the particular moment, and formally through a solicitor, would have been too terrible for you." (WILDE, 2000, p. 24). 
de uma corporalidade de Bosie condizente com o antiethos que busca construir: "(...) parecia esquecer de tua pequena estatura e da inferioridade de tua força..."(WILDE, 2007, p. 1360). ${ }^{20}$

Em um dos inúmeros relatos das lembranças de Wilde sobre sua amizade com Douglas, um trecho é significativo por mostrar o papel desempenhado por uma outra correspondência. Trata-se da primeira carta que Wilde escreveu a Bosie, em razão de uma ajuda que este último tinha lhe solicitado para a apreciação de um poema. Nas palavras de Wilde:

Submeteste à minha aprovação um poema muito bonito da escola de estudantes. Respondi com uma carta cheia de fantásticos concetti literários: comparava-te com Hilas, com Jacinto, com Junquillo, com Narciso ou com alguns daqueles aos quais o Grande Deus da Poesia favoreceu e distinguiu com seu amor. A carta é semelhante a uma passagem dos sonetos de Shakespeare, transportado para um tom menor.

[...] Era - permita que to (sic) diga francamente - o gênero de carta que, em um momento feliz, e até mesmo apetecido, teria escrito a qualquer amável jovem de uma Universidade que me tivesse enviado um poema desse estilo, na certeza de que teria suficiente engenho e cultura para interpretar adequadamente frases fantásticas. Vês a história dessa carta! De tuas mãos passou às de um repugnante companheiro; das deste às de uma quadrilha de chantagista; umas cópias dessa carta são enviadas a meus amigos de Londres e ao diretor do teatro onde se representa minha peça; dão-se-lhe todas as interpretações, menos a normal; circula entre as pessoas o absurdo boato de que tive de pagar avultada soma por haver-te escrito uma carta infamante, e isto constituiu a base da pior acusação de teu pai.

Apresento eu mesmo a carta original perante o Tribunal para mostrar o que realmente é; o advogado de teu pai a denuncia como uma revoltante e insidiosa tentativa de corrupção de menor; a Coroa a utiliza; o juiz apóiase nela com pouca erudição, mas com muita moralidade e por causa dela vou parar na prisão, finalmente. E é este o resultado de haver-te escrito uma carta encantadora." (WILDE, 2007, p. 1362-1363). ${ }^{21}$

${ }^{20 ،}[$...] ]your low stature and inferior strenght...” (WILDE, 2000, p. 22).

${ }^{21 ، " Y o u ~ s e n d ~ m e ~ a ~ v e r y ~ n i c e ~ p o e m, ~ o f ~ t h e ~ u n d e r ~ g r a d u a t e ~ s c h o o l ~ o f ~ v e r s e ~ f o r ~ m y ~}$ approval: I reply by a letter of fantastic literary conceits: I compare you to Hylas, or Hyacinth, Jonquil or Narcisse, or someone whom the great god of Poetry favoured, and honoured with his love. The letter is like a passage from one of Shakespeare's 
Essa citação mostra não só o primeiro contato de Bosie e Wilde, como é explicativa do processo movido pelo Marquês de Queensberry, pai de Douglas, contra Wilde, que culminou em seu julgamento e posterior prisão. Wilde consegue, em poucas palavras, reproduzir o percurso da carta que escreveu para Bosie e que foi uma das provas contundentes para a abertura do julgamento por crime de indecência grave, pelo qual, posteriormente, ficaria enormemente conhecido. Além disso, esse trecho mostra também o papel relevante que as correspondências desempenhavam naquele contexto de produção, como modo privilegiado de comunicação.

Esse trecho incita a seguinte questão: quando Bosie escreveu essa carta a Wilde, solicitando sua apreciação sobre um poema que ele havia escrito, ele se dirigia ao Wilde escritor ainda em ascensão; ao Wilde inscritor reconhecido pelos seus talentos com poemas, ou ainda ao reconhecidamente brilhante ex-aluno de Oxford? O leitor também se vê diante dilema parecido quando lê De Profundis...

As primeiras linhas do trecho anterior revelam o posicionamento do escritor e os preceitos do movimento esteto-decadentista, ${ }^{22}$ ao qual Wilde estava filiado, por meio da invocação das figuras mitológicas Hylas, Hyacinth, Jonquil e Narcisse, conhecidas pela beleza de sua juventude. Outro ponto que revela a instância do escritor neste trecho

sonnets, transposed to a minor key. [...] It was, let me say frankly, the sort of letter I would, in a happy if wilful moment, have written to any graceful young man of either University who had sent me a poem of his own making, certain that he would have sufficient wit or culture to interpret rightly its fantastic phrases. Look at the history of that letter! It passes from you into the hands of a loathsome companion: from him to a gang of blackmailers: copies of it are sent about London to my friends, and to the manger of the theatre where my work is being performed: every construction but the right one is put on it: Society is thrilled with the absurd rumours that $\mathrm{I}$ have had to pay a huge some of money for having written an infamous letter to you: this forms the basis of your father's worst attack: I produce the original letter myself in Court to show what it really is: it is denounced by your father's Counsel as a revolting and insidious attempt to corrupt Innocence: ultimately it forms part of a criminal charge: the Crown takes it up: the Judge sums up on it with little learning and much morality: I go to prison for it at last. That is the result of writing you a charming letter (WILDE, 2000, p. 25-26). (grifo nosso).

${ }^{22} \mathrm{O}$ posicionamento de Oscar Wilde foi abordado de forma mais detalhada em trabalho anterior (RODRIGUES, 2009). 
relaciona-se com a correspondência com o paganismo românico e grego e com a invocação de um Deus que pode preterir um indivíduo ao outro e favorecer com seu amor um mero mortal, dando um dom especial a ele. Esse dom e presente a que Wilde refere-se é o dom de escrever uma poesia, um poema, e não qualquer outro gênero. Essa asserção revela o papel de destaque que a poesia e o poema tinham naquele período literário, tanto que o primeiro reconhecimento que Wilde obteve foi com seu poema Ravena (1878), que recebeu o Newdigate Prize.

É possível destacar ainda outro traço do escritor, como quando Wilde estabelece como parâmetro para sua escrita os talentos de Shakespeare, reconhecendo-o como autor legítimo: "A carta é semelhante a uma passagem dos sonetos de Shakespeare, transposta para tom menor." (WILDE, 2007, p. 1362).23

Algumas observações sobre a cenografia e o ethos se mostram relevantes, no sentido de que a primeira, a cenografia, implicada por De Profundis se constrói por meio de uma crítica à sociedade inglesa, que pode ser representada pelo juiz que julga o caso de Wilde, com pouco conhecimento sobre arte e muita moralidade: "o juiz apóia-se nela [na carta] com pouca erudição, mas com muita moralidade." (WILDE, 2007, p. 1363)." ${ }_{24}$ Essa cenografia se desenvolve apoiando-se em uma cronografia de inadequação do tempo, de não pertencimento. A topografia, por sua vez, firma-se no espaço da arte, que se contrapõe à sociedade inglesa do século 19 . O ethos que o autor busca construir e que emerge do texto apresenta os traços de um incompreendido, de um injustiçado pela sociedade e, na mesma medida, de um connaisseur da arte. Em suma, trata-se de um ethos de alguém com valores diferentes dos da sociedade que o julga, de alguém com dons e valores artísticos, que metamorfoseia vida e arte e que, por isso mesmo, é condenado por essa sociedade. Tem-se um embate entre a arte e o ordinário; a sociedade não é capaz de compreender os signos artísticos, faz um julgamento moral, e, portanto incorreto: "dão-se-lhe todas as interpretações, menos a normal.” (WILDE, 2007, p 1362).25

${ }^{23}$ "The letter is like a passage from one of Shakespeare's sonnets, transposed to a minor key" (WILDE, 2000, p. 25).

24“'Judge sums up on it with little learning and much morality."(WILDE, 2000, p. 26).

25 "every construction but the right one is put on it." (WILDE, 2000, p. 26). 
No final do trecho encontram-se as marcas da ironia de Wilde com a afirmação "E é este o resultado de haver-te escrito uma carta encantadora" (WILDE, 2007, p. 1362-1363), ${ }^{26}$ que evidencia um traço recorrente não apenas do inscritor como também da instância da pessoa, já que Wilde era reconhecido nos salões que frequentava pela fina ironia. A instância da pessoa se manifesta, durante o percurso da carta, em trechos de narrativa pessoal e de descrição de breves ou longos acontecimentos, por exemplo, quando Wilde, ao se dirigir a Bosie, queixa-se que o criado que ele aceitou, como um pedido especial de Bosie, para trabalhos no verão em Goring, serviu como testemunha de acusação em seu julgamento.

O eixo 2 da correspondência, nomeado como "autorreflexão" dedica-se ao momento em que o autor reconhece o valor do sofrimento (da tristeza) como uma grande revelação que mudou sua visão de mundo, incluindo sua visão sobre a Arte. Nesses momentos, a interpenetração da pessoa, do escritor e do inscritor formam um emaranhado tão constitutivo que, quando busca-se apontar uma instância, encontra-se todas ao mesmo tempo.

Nesse eixo, Wilde abre um espaço maior para ponderações existenciais, mas ainda mantém o mecanismo discursivo de reconhecer sua culpa para, em seguida, culpabilizar Bosie:

$\mathrm{O}$ ódio cega a gente. Tu não o sabias. $\mathrm{O}$ amor pode ler na estrela mais longínqua; mas o ódio te cegava de tal modo, que não podias ver mais além do reduzido jardim, cercado e já seco pelo vício. Tua terrível falta de imaginação, o único defeito verdadeiramente fatal de teu caráter, era, absolutamente, o resultado do ódio que respirava em ti (WILDE, 2007, p. 1367). ${ }^{27}$

Wilde discorre sobre como o ódio cega as pessoas e de como o amor é um sentimento maior e nobre, capaz de elevar o ser humano e sua capacidade

26"That is the result of writing you a charming letter." (WILDE, 2000, p. 26).

${ }^{276 " H a t e ~ b l i n d s ~ p e o p l e . ~ Y o u ~ w e r e ~ n o t ~ a w a r e ~ o f ~ t h a t . ~ L o v e ~ c a n ~ r e a d ~ t h e ~ w r i t i n g ~ o n ~ t h e ~}$ remotest star, but Hate so blinded you that you could see no further than the narrow, walled-in, and already lust-withered garden of your common desires. Your terrible lack of imagination, the one really fatal defect of your character, was entirely the result of the Hate that lived in you." (WILDE, 2000, p. 32, grifo nosso). 
de percepção. Em seguida, ele aponta que Bosie estava cego pelo ódio, e isso gerava nele seu grande defeito: "Your terrible lack of imagination" ("Tua terrível falta de imaginação"). Essa expressão, que aparece mais de uma vez em De Profundis, é a mesma expressão utilizada em The Picture of Dorian Gray, pela personagem Lord Henry, para descrever um dos grandes defeitos da burguesia. $\mathrm{O}$ emprego da mesma expressão não parece desprovido de significância, em termos de funcionamento da autoria, figurando, ao que indica, como um indício da inseparabilidade das três instâncias.

As acusações a Bosie continuam, mas sempre mantendo o tom professoral e complacente:

Como vês, não tenho mais remédio senão narrar tua vida diante de ti e para ti; assim compreenderás. Conhecemo-nos há mais de quatro anos; passamos juntos metade desse tempo e a outra metade tive de sofrê-la na prisão como paga dessa nossa amizade.

[...] e não percebes que és o verdadeiro autor da terrível tragédia. [...] E não tinha eu o menor desejo de dizer-te o que deveria ter gritado teu próprio coração. $\mathrm{O}$ que, sem dúvida, te teria gritado se não o houvesses endurecido e embotado com ódio. Tudo tem de brotar na gente, espontaneamente. E torna-se por completo inútil querer dizer a alguém uma coisa que nem sente, nem pode compreender. Se agora te escrevo desta forma é tão-somente porque teu próprio mutismo, teu comportamento durante minha longuíssima reclusão assim o exige (WILDE, 2007, p. 1370-1371). ${ }^{28}$

Quando Wilde relata sobre o tempo em que os dois, ele e Bosie, se conhecem, manifesta-se não só a instância da pessoa, com seu componente

\footnotetext{
${ }^{28}$ You see that I have to write your life to you, and you have to realise it. We have known each other now for more than four years. Half of the time we have been together: the other half I have had to spend in prison as result of our friendship. [...] you were the true author of the hideous tragedy did not occur to you. [...] I did not desire to be the one to tell you what your own heart should have told you, what it indeed would have told you if you had not let Hate harden it and make it insensate. Everything must come to one out of one's own nature. There is no use in telling a person a thing that they don't feel and can't understand. If I write to you now as I do it is because your own silence and conduct during my long imprisonment have made it necessary. (WILDE, 2000, p. 35-36, grifo nosso).
} 
biográfico, mas também a instância do inscritor, perceptível pela presença do sarcasmo, da ironia como figura de estilo, como é possível observar no trecho anterior em negrito. Nesse trecho, ao comentar a duração da amizade, Wilde sarcasticamente divide a amizade dos dois em dois períodos equivalentes: o primeiro, eles passaram juntos, o segundo ele passa na prisão como consequência dessa mesma amizade. O sarcasmo é recorrente em outros textos do autor, por exemplo em The Picture of Dorian Gray: "Você é um tolo, pois há apenas uma coisa no mundo pior do que ser comentado e é ser ignorado." (WILDE, 2009, p. 15); ${ }^{29}$ ou ainda, no mesmo texto, "Você parece esquecer que sou casado e que um encanto do casamento é fazer uma vida de enganos necessária a ambos os lados." (WILDE, 2009, p. 18). ${ }^{30}$ Nesse sentido, em função da recorrência, é que se considera o sarcasmo como um traço da instância do inscritor.

Wilde se apresenta como o portador de um aprendizado que ele não gostaria de ensinar, mas que não lhe sobra outra alternativa, já que o ódio tinha tornado o coração de Bosie duro e insensato. Nesse mesmo momento, em que a instância da pessoa manifesta-se na forma de uma conversa franca com o outro, a instância do escritor ganha visibilidade por meio da exaltação da experiência ("E torna-se por completo inútil querer dizer a alguém uma coisa que nem sente, nem pode compreender."), uma vez que essa valorização é um traço do posicionamento estetodecadentista.

Wilde, neste eixo, também irá enfatizar as tentativas frustradas de pôr fim à amizade com Bosie e como a não realização dessa ação culminou em sua ruína. Ao discorrer sobre sua história exposta, retomada e reapropriada, faz a seguinte reflexão:

Não era necessário expor, com a clareza que aqui o faço, meus reiterados
esforços para romper uma amizade que prejudicava minha arte, minha
posição social e minha pessoa como membro da sociedade. Não queria
eu tampouco que contasses aqueles escândalos repetidos com verdadeira
monotonia, nem que publicasses a série de telegramas maravilhosos que
me dirigiste com uma estranha mistura de romantismo e de interesse

29" It is silly of you, for there is only one thing in the world worse than being talked about, and that is not being talked about" (Wilde, 2009, p. 15).

${ }^{30 "}$ You seem to forget that I married, and the one charm of marriage is that it makes a life of deception necessary for both parties" (idem, p. 18). 
metalizado, nem que reproduzisses aqueles parágrafos tão revoltantes e cruéis de tuas cartas que me foi preciso suportar. Mas acreditei que teria sido muito oportuno, tanto por ti como por mim, que te erguesses contra a interpretação que deu teu pai à nossa amizade [...]. Atualmente já está convertida em fato histórico, que se divulgou, em que todos crêem, que ficou como artigo de fé. O pastor a aproveita para tema de seus sermões e o moralista toma-a como base de suas inúteis prédicas. E eu, um homem reverenciado por todos, tenho de acatar a sentença de um cretino ou de um bufão.

Como digo antes nesta carta, e com certa amargura o reconheço, o mais irônico da questão é o fato de continuarem considerando teu pai como o herói de uma obra moral e a ti compararem com o menino Samuel e eu, em troca, ocupe um lugar entre Gilles de Retz e o Marquês de Sade..." (WILDE, 2007, p. 1378-1379). ${ }^{31}$.

O início desse trecho configura-se como uma justificativa da escrita da carta, o porquê do fornecimento de certos detalhes, que Wilde não gostaria de fornecer, mas que se sentia forçado a expô-los em razão da ruína que sua vida havia alcançado como artista, como homem de posição social e pelo tom que a história de sua vida tinha adquirido. Nesse momento, percebe-se a manifestação, ao mesmo tempo, da instância da pessoa, que se justifica e reclama da postura de Bosie, e da instância do escritor, que vê sua trajetória no campo deturpada pelos acontecimentos,

\footnotetext{
31،My incessant attempts to break off a friendship that was so ruinous to me as an artist, as a man of position, as a member of society even, need not have been chronicled with the accuracy with they have been set down here. Nor would I have desired you to have described the scenes you used to make with such almost monotonous recurrence: nor to have reprinted your wonderful series of telegrams to me with their strange mixture of romance and finance; nor to have quoted from your letters the more revolting or heartless passages, as I have been forced to do. Still, I thought it would have been good, as well for you as for me, if you had made some protest against your father's version of our friendship [...]. That version has know actually passed into serious history: it is quoted, believed, and chronicled: the preacher has taken it for his text, and the moralist for his barren theme: and $I$ who appealed to all ages have had to accept my verdict from one who is an ape and a buffoon. I have said, and with some bitterness I admit, in this letter that such was the irony of things that your father would live to be hero of a Sunday-school tract: that you would rank with the infant Samuel: and that my place would be between Gillez de Retz and the Marquis de Sade. (WILDE, 2000, p. 44-45, grifo nosso).
} 
ao afirmar que a grande ironia é o pai de Bosie ser visto como o herói de um folheto dominical, enquanto ele figuraria ao lado de autores considerados "malditos", como Gillez de Retz e Marquês de Sade.

De Profundis é uma produção do espaço associado com a dimensão da figuração bem acentuada, mas, ao mesmo tempo, de maneira inseparável, nela, o autor busca construir uma trajetória singular em um conjunto. É possível perceber esse funcionamento no trecho a seguir, no qual Wilde faz uma autorreflexão sobre os rumos de sua vida, permitindo que se manifestem as três instâncias do funcionamento da autoria. É um trecho emblemático da carta, revelador não só do funcionamento da autoria, tal como postulado por Maingueneau, mas também de indícios da forma como o próprio Wilde via a trajetória de sua obra e como ele "administrava" a dimensão da figuração:

Tenho de dizer a mim mesmo que nem tu nem teu pai, embora vos tivésseis multiplicado por mil, poderíeis ter aniquilado um homem como eu.

Necessito dizer a mim mesmo que tenho culpa de tudo, que ninguém se aniquila senão por sua própria vontade. [...] Se terrível foi o que o mundo me fez, muito mais terrível foi o dano que causei a mim mesmo.

Estava eu relacionado, de modo simbólico, com a arte e a cultura de meu tempo. Havia percebido isto no declive de minha vida e havia obrigado meus contemporâneos a aceitá-lo. Poucos homens chegam a alcançar em vida uma posição semelhante à minha. Em geral, são descobertos pelos historiadores ou pelos críticos depois que eles e com eles sua época desapareceram. Comigo foi absolutamente diferente. Byron foi uma figura simbólica, relacionada com a paixão e a lassidão de sua época. Eu aspirei a algo mais nobre, mais permanente, de resultado mais vital e de maior alcance. Os deuses tinham sido generosos comigo. Possuía gênio, um nome distinto, uma elevada posição social, brilho e audácia intelectual. Fazia da arte uma filosofia e da filosofia uma arte. Alterava as mentes dos homens e as cores das coisas. Não havia nada que eu dissesse ou fizesse que não maravilhasse as pessoas. Entreguei-me ao teatro, a forma artística mais objetiva que se conhece, e fiz do teatro um modo de expressão tão pessoal como a ode ou o soneto, ao mesmo tempo que ampliava seus domínios enriquecia sua caracterização. $\mathrm{O}$ teatro, o romance, o poema em prosa, o poema em verso, o diálogo sutil e fantástico, tudo quanto eu tocava embelecia-se com uma nova espécie de beleza; à própria verdade dei não só verdadeiro, mas também o falso, 
como província própria, e demonstrei que tanto o falso como o verdadeiro não são mais do que formas da existência intelectual. Considerei a arte como a suprema realidade e a vida como um simples modo de ficção. Alimentei a imaginação de meu século até criar o mito e a lenda em redor de mim. Reuni todos os sistemas em uma frase e toda a existência em um epigrama. [...] Divertia-me ser um flâneur, um dândi, um homem da moda. [...] O que foi para mim o paradoxo na esfera do pensamento, foi-o a perversidade no círculo da paixão.

[...] Agora descobri algo dentro de mim que me diz que tudo no mundo, inclusive o sofrimento, tem uma razão de ser, que há algo oculto no meu coração, como um tesouro, e que este tesouro é a humildade. É a última e a melhor coisa que me restou, minha derradeira descoberta, o ponto de partida de uma era nova. Surgiu do mais profundo do meu ser e chegou em tempo, nem antes nem depois do que era preciso. Se alguém mo tivesse dito, tê-lo-ia negado: se mo tivessem trazido, tê-lo-ia rejeitado. Como o encontrei quero conservá-lo... [...]. Sou mais do que nunca individualista. Não há nada que alcance mais valor que aquilo que sai de nós mesmos. Estou procurando novo modo de auto-realização e isto é o que por ora me interessa (WILDE, 2007, p. 1388-1390). ${ }^{32}$

${ }^{32}$ I must say to myself that neither you nor your father, multiplied a thousand times over, could possibly ruined a man like me: that I ruined myself: and nobody, great or small, can be ruined except by his own hand. [...] Terrible as what you did to me was, what I did to myself was far more terrible still.

I was a man who stood in symbolic relations to the art and culture of my age. I had realized this for myself at the very dawn of my manhood, and had forced my age to realized it afterwards. Few men hold a such position in their own lifetime and have it so acknowledged. It is usually discerned, if it discerned at all, by the historian, and the critic, long after both the man and his age have passed away. With me it was different. I felt it myself, and made others feel it. Byron was a symbolic figure, but his relations were to the passion of his age and its weariness of passion. Mine were to something more noble, more permanent, of more vital issue, of a larger scope.

The gods had given me almost everything. I had genius, a distinguished name, high social position, brilliancy, intellectual daring: I made art a philosophy, and philosophy a art: I altered the minds of men and the colours of thing: there was nothing I said or did that not make people wonder: I took the drama, the most objective form of known to art, and made it as personal a mode of expression as the lyric or the sonnet, at the same time that I widened its range and enriched its characterization: drama, novel, poem in rhyme, poem en prose, subtle or fantastic dialogue, whatever I touched I made beautiful in a new mode of beauty: to truth itself I gave what is false no less than what is true as its rightful province, and showed that the false and the true are merely forms 
As primeiras linhas revelam traços das instâncias da pessoa e do inscritor. A manifestação da primeira é perceptível quando Wilde, de maneira enfática, diz que nem Bosie, nem o pai de Bosie poderiam arruinar um homem como ele, colocando em cena um aspecto de sua biografia. Com relação à instância do inscritor, ela se manifesta logo em seguida na máxima: "ninguém se aniquila senão por sua própria vontade", ${ }^{33}$ uma característica do modo de enunciar de Oscar Wilde no espaço de produção canônico, e já apontada em outros momentos neste artigo. Outro ponto a ser destacado no trecho selecionado é a referência a Byron. Essa referência é uma forma de Wilde relacionar-se com o thesaurus literário, denotando traços do posicionamento do escritor.

Ainda, nesse trecho, é possível perceber o funcionamento das dimensões de figuração e regulação, que decorre do imbricamento das instâncias da pessoa, do escritor e do inscritor. A construção da identidade criadora de Wilde (figuração) e a negociação desse autor para inserir sua obra num dado estado do campo (regulação) resultam, ao mesmo tempo, da "pessoa", que possui "um nome distinto, uma elevada posição social" ${ }^{34}$ do "inscritor" que possui "brilho e audácia intelectual" ${ }^{35}$

of intellectual existence. I treated Art as the supreme reality, and life as a mere mode of fiction: I awoke the imagination of my century so that it created myth and legend around me: I summed up all systems in a phrase, and all existence in an epigram.

[...] I amused myself with being a flâneur, a dandy, a man of fashion. [...] What paradox was to me in the sphere of thought, perversity became to me in the sphere of passion.

[...] Now I find hidden away in my nature something that tells me that nothing in the whole world is meaningless, and suffering least of all. That something hidden away in my nature, like a treasure in a Field, is Humility.

It is the last thing left in me, and the best: the ultimate discovery at which I have arrived: the start-point for a fresh development. It has come to me right out of myself, so I know that it has come at the proper time. It could not have come before, nor later. Had anyone told me of it, I would have rejected it. Had it been brought to me, I would have refused it. As I found it, I want to keep it. [...] I am far more of an individualist than I ever was. Nothing seems to me of the smallest value except what one get out of oneself. My nature is seeking a fresh mode of self-realisation. That is all I am concerned with. (WILDE, 2000, p. 57-59).

33" "nobody, great or small, can be ruined except by his own hand"

${ }^{344}$ "a distinguished name, high social position"

35"brilliancy, intellectual daring" 
e do "escritor" que, inscrito em um posicionamento esteto-decadentista no campo literário, defende um de seus grandes preceitos em relação à arte e à vida, a saber, "fazer da arte uma filosofia e da filosofia uma arte". ${ }^{36}$ Esse funcionamento acaba por esbarrar na construção da lenda desse autor e, da mesma maneira, na inseparabilidade do posicionamento de Wilde e da auto-gestão de sua lenda: "alimentei a imaginação de meu século até criar o mito e a lenda em redor de mim.". ${ }^{37}$

Ainda no mesmo trecho, Wilde resume algumas de suas características como inscritor: "Reuni todos os sistemas em uma frase e toda existência em um epigrama". ${ }^{38}$ Ele revela igualmente traços das instâncias da pessoa e do escritor de maneira imbricada: "Divertia-me ser um flâneur, um dândi, um homem da moda." ${ }^{39}$ Quando Wilde utiliza a expressão "I amused myself", o uso do pronome pessoal "I" (eu) em uma correspondência em que se auto predica como flâneur, um dandy, um homem da moda, nos leva a relacionar as instâncias da pessoa, que se manifesta como uma forma de subjetivação, e do escritor, já que a figura do dandy encarna o posicionamento esteto-decadentista.

Com base nesses apontamentos, e considerando, em especial, o excerto anterior, é possível perceber a emergência de um ethos que configura um enunciador à frente de seu tempo e, por isso, incompreendido e injustiçado, mas que encontrou o objetivo maior da vida e a justificativa do porquê dos acontecimentos vividos, que não vieram nem antes nem depois, mas no momento certo: "É a última e a melhor coisa que me restou, minha derradeira descoberta, o ponto de partida de uma era nova. Surgiu do mais profundo do meu ser e chegou em tempo, nem antes nem depois do que era preciso." ${ }^{\prime 4}$

É nesse sentido, e considerando o eixo da autorreflexão, que o manuscrito De Profundis pode ser compreendido como uma espécie de "viagem interior", evidenciando a condição paratópica do autor que, mesmo tendo sido encarcerado pela sociedade, é capaz de transfigurar os dois anos na prisão em um aprendizado interior, superando sua condição

\footnotetext{
36“"made art a philosophy, and philosophy a art".

${ }^{37}$ "I awoke the imagination of my century so that it created myth and legend around me" ${ }^{38}$ "I summed up all systems in a phrase, and all existence in an epigram."

39،"I amused myself with being a flâneur, a dandy, a man of fashion."

40"It is the last thing left in me, and the best: the ultimate discovery at which I have arrived: the start-point for a fresh development. It has come to me right out of myself, so I know that it has come at the proper time."
} 
de preso e promovendo uma autotranscedência capaz, ela mesma, de tornar sua obra, sua arte ainda melhores.

Quando Wilde, em De Profundis, mergulha na nomeada "autorreflexão", o emaranhado das instâncias da autoria possibilita que se coloque a todo momento a questão: a quem se pode atribuir a voz que narra? No caso desse texto de Oscar Wilde, essa indeterminação de fronteiras pode se mostrar ainda mais generalizada, já que embora a carga da condenação seja imputada à pessoa, o escritor foi igualmente julgado e condenado, seu percurso no campo literário foi usado, no julgamento, como prova de sua perversão. Wilde encarnou o estetismo-decadentista até as últimas consequências, e o postulado da transformação da vida em obra de arte foi um mantra aplicado com maestria.

Quando Wilde reconhece o valor do sofrimento, da tristeza, ele não o faz de maneira desvinculada de seu posicionamento, contrariamente, ele aplica os elementos da melancolia também como uma forma de autoconhecimento, de experiência. $\mathrm{O}$ autor faz uma analogia entre sua vida e um jardim de árvores frutíferas, do qual ele diz que experimentaria todos os frutos, e assim o fez. Todavia, segundo ele, seu erro foi confinarse nas árvores que estavam no lado do sol dourado e evitar o outro lado do jardim, por suas sombras e melancolias. Nessa autorreflexão realizada por meio de uma analogia, o autor, em um mesmo movimento, busca gerir o contexto de sua produção e legitimar e criar uma unidade para sua arte; para isso finaliza essa reflexão com um enunciado que justifica e, ao mesmo tempo, esclarece esse apreço pela melancolia, pelo outro lado do jardim: "Of course all this is foreshadowed and prefigures in my art" (WILDE, 2000, p. 70) ("Na realidade, tudo isso está simbolizado e previsto em meus livros." (Op. cit., p. 1398)), para em seguida citar alguns de seus textos que continham, às vezes de forma mais contundente, às vezes de forma velada ou nas entrelinhas, pitadas de melancolia e do valor do sofrimento.

Essa aura de sofrimento e tristeza, que é, todavia, transmutada em aprendizado, é a entrada para o que foi nomeado eixo 3, "Deus". Essa entrada se dá por meio da comparação do artista com Cristo ("Eu vejo uma conexão muito mais íntima e imediata entre a verdadeira vida de Cristo e da verdadeira vida do artista..." (WILDE, 2007, 1399)), ${ }^{41}$ comparação que é, em seguida, aprofundada:

${ }^{41 " I}$ see a far more intimate and immediate connection between the true life of Christ and the true life of the artist..." (Op. cit., p. 71). 
[...]E não só podemos discernir em Cristo essa íntima união de sua personalidade com a perfeição, que constitui a diferença real entre o movimento clássico e o movimento romântico na vida, mas também a própria base de sua natureza era a mesma da natureza do artista: uma imaginação intensa e fulgurante. [...] Sem dúvida alguma, o lugar de Cristo se acha entre os poetas." (WILDE, 2007, p. 1399-1400). ${ }^{42}$

Cristo seria o grande precursor do romantismo e, portanto, um verdadeiro avant-garde, do mesmo modo que, de acordo com o próprio Wilde, Cristo era um individualista, "Cristo, acima de tudo, é o supremo individualista" (WILDE, 2007, p. 1402). ${ }^{43}$ Para ele, "A humildade, como aceitação artística de todas as experiências, é, simplesmente, um modo de expressão. O que Cristo sempre busca é a alma do homem." (WILDE, 2007, p. 1402). ${ }^{44}$ Wilde prega, em toda extensão da carta, no sentido mesmo de propagar um sermão, os preceitos do movimento esteto-decadentista (como a aceitação artística de todas as experiências). $\mathrm{O}$ paralelo entre Cristo e o verdadeiro artista, permeia toda a parte final da carta, havendo mesmo a afirmação:

Se algum dia voltar a escrever, no sentido de produzir uma obra artística, existem dois temas precisamente a respeito dos quais desejo exprimirme: um, é "Cristo como precursor do movimento romântico na vida", e o outro, "A vida artística considerada na sua relação com a conduta" (WILDE, 2007, p. 1407). ${ }^{45}$

Esse trecho também permite localizar a instância do escritor que projeta um percurso no campo, ao relatar seus planos de escrita:

\footnotetext{
42"“and makes Christ the true precursor of the romantic movement in life, but the very basis of his nature was the same as that of the nature of the artist, an intense and flamelike imagination. [...] Christ's place indeed is with the poets. (WILDE, 2000, p. 72). 43“"the most supreme of Individualists" (WILDE, 2000, p. 75).

44،"humility, like artistic acceptance of all experiences, is merely a mode of manifestation. It is man's soul that Christ is always looking for" (WILDE, 2000, p. 75).

45"If I ever write again, in the sense of producing artistic work, there are just two subjects in which and through which I desire to express myself: one is "Christ, as the precursor of the Romantic movement in life": the other is "the Artistic life considered in its relation to Conduct" (WILDE, 2000, p. 82).
} 
"Se algum dia voltar a escrever, [...], existem dois temas precisamente a respeito dos quais desejo exprimir-me." ${ }^{.46}$

Cristo, além do primeiro e maior individualista, era também, segundo Wilde, o supremo poeta, por ser sua vida o mais belo poema. Novamente, Wilde concebe Cristo a partir do preceito base do posicionamento esteto-decadentista, a saber, o da inseparabilidade entre vida e arte, acentuando, novamente, a instância do escritor.

Derivando de cena genérica de uma correspondência, Oscar Wilde enuncia por meio de uma cenografia que se alterna entre uma epístola, um diário íntimo e um manifesto; o autor relata não só sua relação com Bosie, mas uma rede de lembranças que alcançam seu calvário na prisão, sua autorreflexão, a descoberta de Deus e a valorização de Cristo. A carta termina num tom de ensinamento para Bosie, quando Wilde diz:

Vieste a mim para aprender o gozo da vida e o gozo da arte. Talvez tenha sido eu escolhido para ensinar-te algo mais maravilhoso: a significação e a beleza da dor. Teu amigo que te quer, Oscar" (WILDE, 2007, p. 1437). ${ }^{47}$

Esse trecho revela de maneira privilegiada o funcionamento da instância da pessoa, uma vez que nele se relembra o motivo da aproximação entre Wilde e Bosie, e também em função da expressão "Teu amigo que te quer, Oscar.", ${ }^{48}$ que denota o cunho íntimo da correspondência.

\section{Considerações finais}

Após a análise da carta em três eixos e o apontamento, em cada um deles, do funcionamento da autoria por meio das instâncias autorais, ocorreu concomitantemente a emergência de um ethos, a construção de uma cenografia e de um posicionamento na interlíngua. É possível afirmar que estas três categorias funcionam como embreantes (elementos de

\footnotetext{
46"If I ever write again [...] there are just two subjects in which and through which I desire to express myself"

47" You came to me to learn the Pleasure of Life and the Pleasure of Art. Perhaps I am chosen to teach you something much more wonderful, the meaning of Sorrow, and its beauty. Your affectionate friend Oscar Wilde. (WILDE, 2000, p. 118).

48" Your affectionate"
} 
ligação) por se configurarem como um modo de o texto gerir o contexto. Esclarece-se esse ponto a seguir.

O ethos é um embreante do posicionamento do escritor, visto que essa noção, tal como postulada por Maingueneau (2005), decorre da semântica de um discurso. Trata-se de uma figura de enunciador que não é o autor, é uma figura que emerge do texto, do discurso, do posicionamento, sendo, pois, uma categoria de enunciação. O ethos é também uma categoria que decorre da instância do inscritor, porque refere-se a um modo de enunciação e, em alguma medida, portanto, a um estilo. Também pode relacionar-se à instância da pessoa, basta considerar a corrente confusão em associar o ethos à pessoa do autor. ${ }^{49}$

Considerando as análises, é possível perceber, num momento inicial (eixo 1), a emergência de um ethos de injustiçado; em seguida, a emergência de um ethos de vanguarda, vinculado à figura de um homem à frente de seu tempo (ethos que se manifesta sobretudo no eixo 2); por fim, a emergência de um ethos messiânico (construído no eixo 3): ele foi julgado, castigado, crucificado injustamente, uma vez que não cometeu o pecado de que foi acusado, mas, ainda sim, após toda essa injustiça, transfigurou o encarceramento em um experiência libertadora. A junção desses ethé acaba por aprofundar a paratopia do autor.

Sobre a cenografia, pode-se dizer que Oscar Wilde constrói uma cenografia de via crucis, ancorada em uma intertextualidade mostrada externa (referindo-se a textos de outro(s) campo(s)), com textos do campo religioso, o que, por sua vez, configura-se, como uma forma de interdiscursividade, pelo fato de fazer aliança com certo posicionamento). Essa cenografia que se constrói não é aleatória, ela emerge como a forma possível de transcendência do espaço físico da prisão.

Do posicionamento do escritor na interlíngua tem-se como resultado o código linguageiro da obra, reconhecível por meio de certos traços de estilo (instância do inscritor). Todavia, no livro Discurso literário Maingueneau parece só se referir à interlíngua quando trata das produções ligadas ao espaço canônico. Entretanto, na análise das produções do espaço associado no regime elocutivo, como é o caso de De Profundis, permite-se, pela manifestação das instâncias do inscritor e do escritor, a possibilidade de falar de posicionamento na interlíngua

\footnotetext{
${ }^{49}$ Aborda-se essa confusão entre o ethos que emerge de um texto e a associação à pessoa do autor de maneira mais detalhada em RODRIGUES (2009).
} 
nas produções desse espaço enunciativo, não sendo, pois, a interlíngua um conceito produtivo apenas às produções do espaço canônico.

Tendo em vista todas as considerações feitas, é possível afirmar que o funcionamento da autoria, como concebido por Maingueneau, é a reafirmação do postulado de que o texto é uma forma de gestão do contexto e, nesse sentido, do caráter discursivo da literatura, que não é uma zona insular, e sim o resultado complexo de uma produção cultural também complexa, regida por normas de funcionamento próprias, ancoradas em processos históricos.

\section{Referências}

HOLLAND, M. Introduction. In: WILDE, O. The complete letters of Oscar Wilde. London: Fourth Estate, 2000. 1270 p.

http://dx.doi.org/10.1215/9780822380382-001

London: Collins, 2003[1994].

HOLLAND, V. Introduction. In: WILDE, O. Complete works of Oscar Wilde. London: Collins, 2003[1966].

http://dx.doi.org/10.4324/9780203464441_introduction

MAINGUENEAU, D. Discurso literário. São Paulo: Contexto, 2006.

RODRIGUES, K. C. Cenografia, ethos e autoria: uma abordagem discursiva do romance The Picture of Dorian Gray de Oscar Wilde. Dissertação (Mestrado em Linguística) - Universidade Federal de Uberlândia, Programa de Pós-graduação em Estudos Linguísticos, Uberlândia: 2009.

WILDE, O. De Profundis: epistola in carcere et vinculis. New York: Modern Library, 2000. 136 p.

. De Profundis: epistola in carcere et vinculis. In: . Obra completa. Rio de Janeiro: Nova Aguilar, 2007.

. De Profundis: epistola in carcere et vinculis. In:

Complete Works of Oscar Wilde. London: Collins, 2003.

. O retrato de Dorian Gray. Rio de Janeiro: Civilização Brasileira, 2002. $251 \mathrm{p}$. 
. O retrato de Dorian Gray. Ed. bilíngue. São Paulo:

Landmark, 2009. $224 \mathrm{p}$.

. The picture of Dorian Gray. London: Penguin Books, 2003.

$304 \mathrm{p}$.

. The complete letters of Oscar Wilde. London: Fourth

Estate, 2000. $1270 \mathrm{p}$. 